\title{
LINFOMA/LEUCEMIA T DEL ADULTO: ENTIDAD PREVALENTE EN SUDAMÉRICA
}

\author{
ADULT LYMPHOMA / LEUKEMIA T: PREVALENT ENTITY IN SOUTH AMERICA \\ Brady E. Beltran', Jorge Castillo,
}

El Linfoma/Leucemia T del adulto es una entidad linfoproliferativa T agresiva asociado al retrovirus, HTLV-1.

La infección por HTLV-1 es endémica en Japón, Caribe, África, Sudamérica y en el Medio Este. En Sudamérica, tenemos a Perú, Brasil, Colombia y Chile.

El Perú es endémico para este virus ${ }^{(1-3)}$. La prevalencia del retrovirus en Europa y USA es menor del $1 \%$ pero en Perú se estima alrededor del $3 \%$ de la población adulta sana es portadora del retrovirus ${ }^{(4,5)}$.

De Chile, existen varios reportes de ATLL desde el año 1992 por la Dra. Cabrera y col.(6,7,8).

Otras enfermedades causadas por el retrovirus incluyen la paraparesia espástica tropical, uveítis, dermatitis infectiva, y otros desórdenes reumatológicos, psiquiátricos e infecciosos ${ }^{(9)}$.

Solo $2 \%$ a $4 \%$ de los portadores desarrollarán ATLL ${ }^{(10)}$. Los genes virales involucrados en la transformación maligna son Taxy $\mathrm{HBZ}^{(11,12)}$.

Cinco tipos clínicos son identificados en esta enfermedad: smoldering, crónica, cutánea, linfomatosa y aguda. Sin embargo, las formas aguda y linfomatosas son las más agresivas y también las más prevalentes.

Con respecto al pronóstico, los factores de mal pronóstico son: estadío clínico, el status perfomance, la edad, la albúmina y el receptor soluble de IL-2 ${ }^{(13)}$.

La sobrevida de las formas agudas puede ser de 2 meses mientras que las formas linfomatosas pueden tener un tiempo de sobrevida de alrededor 9 meses.

El tratamiento para las formas leucémicas es el Interferón alfa más zidovudina; la forma linfomatosa responde a quimioterapia ${ }^{(14,15)}$. El trasplante alogénico puede ser la única forma curativa de la enfermedad.

En el presente número de la revista, se presenta una revisión completa de esta entidad realizada por la Dra.

Cabrera y col.

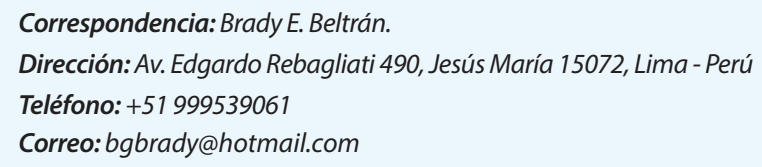

Citar como: Brady E. Beltran. Linfoma/Leucemia T del adulto: entidad prevalente en sudamérica. Rev Rev. Fac. Med. Hum. Abril 2020; 20(2):178-179. DOI 10.25176/RFMH.v20i2.2914 


\section{REFERENCIAS BIBLIOGRÁFICAS}

1. Carrasco A.,Beltrán B et al.clinicalandphenotypic characteristics of adult t-cell leukemia / lymphoma - report of 36 cases in lima-perú. proceeding book eha 2001,poster.

2. Pimentel P, Beltrán B, Carrasco A. clinical characteristics of lymphomatous form of adult t cell lymphoma-leukemia in peru proceedings book asco 2005 abstract 6728 .

3. Beltran B, Carrasco A. clinical outcomes in adult t leukemia / lymphoma: report of 55 cases from peru. proceeding book ash 2005, abstract 479 .

4. Sanchez-Palacios $C$, et al. Seroprevalence and risk factors for human t-cell lymphotropic virus (htlv-i) infection among ethnically and geographically diverse peruvian women. International Journal of infectious diseases 2003; 7 132-137.

5. Alarcón Jo, et al. High endemicity of human t-cell lymphotropic virus type 1 among pregnant women in peru. Journal of acquired immune deficiency syndromes 2006; 42: 604-609

6.Cabrera me, gray am, cartier I, et al. simultaneous adult t-cell leukemia/ lymphoma and sub-acute polyneuropathy in a patient from Chile. Leukemia $1991 ; 5: 350-353$.

7. Cabrera Mec, Majlis AL, Labra SG, et al. Estudio inmunologico de enfermedades linfoproliferativas. rev me'd chile 1992; 120: 772-777.
9. Proietti FA, Carneiro-Proietti AB, Catalan-Soares BC, et al. Oncogene. global epidemiology of htlv-i infection and associated diseases 2005 ;24(39):6058-68

10. International Agency for Research on Cancer. IARC monographs on the evaluation of carcinogenic risks to humans, volume 100B. Biological Agents. Lyon (France): IARC; 2012. Available at: http://monographs.iarc.fr/ENG/ Monographs/vol100B

11. Brand $H$, Alves JGB, Pedrosa F, Lucena-Silva N. Leucemia de células $T$ do adulto. Rev Bras Hematol Hemoter. 2009; 31(5):375-83

12. Matsuoka M. Human T-cell leukemia virus type I (HTLV-I) infection and the onset of adult T-cell leukemia (ATL). Retrovirology. 2005; 2:27.

13. Katsuya H, Yamanaka T, Ishitsuka K, Utsunomiya A, Sasaki H, Hanada S, et al. Prognostic index for acute- and lymphoma-type adult T-cell leukemia/ lymphoma. J Clin Oncol. 2012; 30(14):1635-40 12

14. Ministério da Saúde - Secretaria de Vigilância da Saúde. Portaria n. 54 de 18/07/2016 - Aprova o Protocolo de Uso da Zidovudina para Tratamento do Adulto com Leucemia/Linfoma Associação ao Vírus HTLV-1. Diário Oficial da União. 2016. Available in: http://bvsms.saude.gov.br/bvs/saudelegis/ svs/2016/prt0054_18_07_2016.html.

15. Bazarbachi A, Plumelle Y, Carlos Ramos J, Tortevoye P, Otrock Z, Taylor G, et al. Meta-analysis on the use of zidovudine and interferon-alfa in adult T-cell leukemia/lymphoma showing improved survival in the leukemic subtypes. J Clin Oncol. 2010; 28(27):4177-83

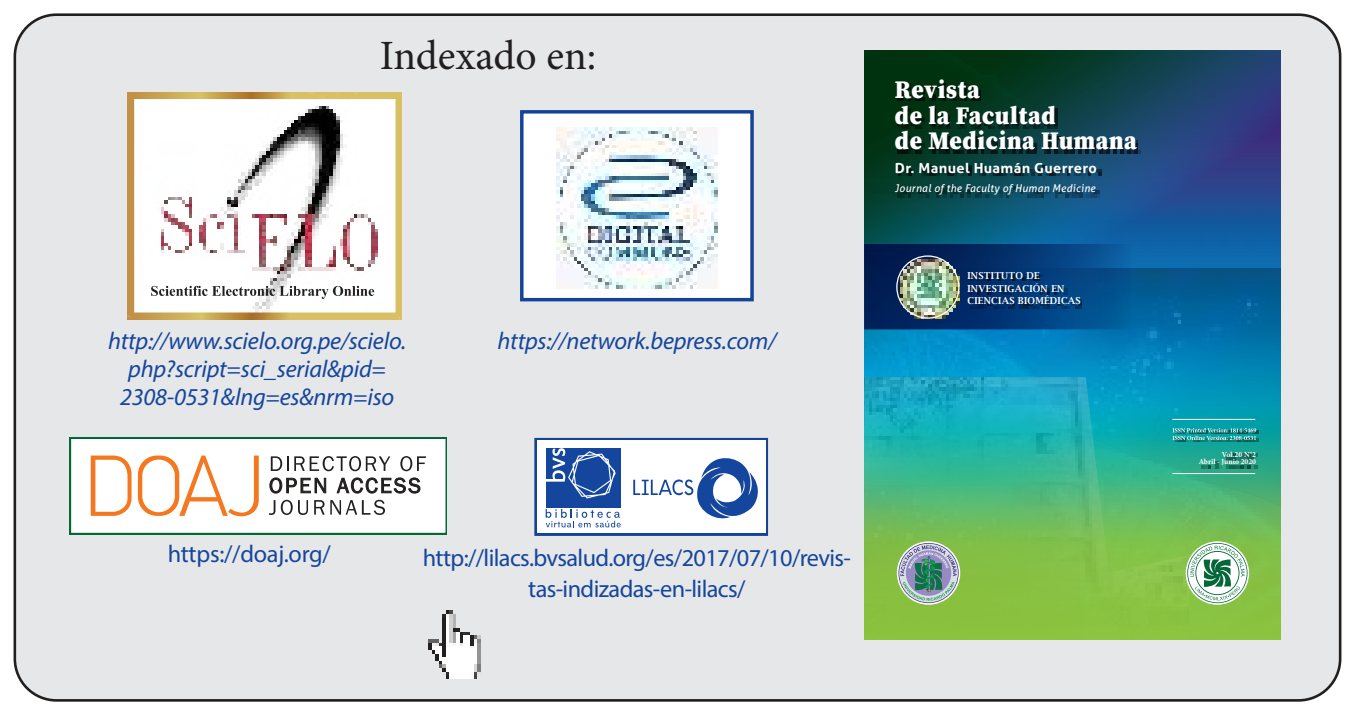

